\title{
Startup Engagement as Part of the Technology Strategy Planning - How Rheinmetall Automotive Increases Innovation by Using Corporate Venturing
}

\author{
Martin Neumann ${ }^{1}$, Dominik Hintzen ${ }^{2}$, Andreas Riel ${ }^{3}$, \\ Gert Waldhausen ${ }^{1}$, Heinrich Dismon ${ }^{1}$ \\ ${ }^{1}$ Rheinmetall Automotive AG, Karl-Schmidt-Straße 2-8, 74172 Neckarsulm, Germany \\ ${ }^{2}$ Fontys International Business School, Tegelseweg 255, 5912 BG Venlo, Netherlands \\ ${ }^{3}$ Grenoble Alps University, G-SCOP Laboratory, 46 av. Félix Viallet, 38031 Grenoble, France
}

\begin{abstract}
In a fast changing environment that is affected by global megatrends, disruptive technological developments and a growing number of new market players, global tier-one suppliers to the automotive industry have to adapt their technology strategy planning by considering current trends in innovation management to maintain their prevailing leading position. This paper presents Rheinmetall Automotive's approach to adopt modern Open Innovation paradigms with a focus on outside-in innovation through Corporate Venturing. Embedded in their Technological Direction Development Process, Rheinmetall Automotive has developed a strategic model to plan startup engagement to improve the current product development and enhance further diversification. Here we describe the several steps how this company-specific strategic model was designed and what prerequisites have to be taken into account to introduce the model in a corporate context.
\end{abstract}

Keywords: corporate venturing, startup engagement, strategy planning, innovation management, automotive supplier industry

\section{Introduction}

A fundamental transformation of transport and mobility patterns, which is already underway, calls for new products and solutions that protect the climate, preserve our environment and guarantee sustainability as well as cope with significant technical, economic, ecologic, regulatory, social and political changes towards experiencing, utilizing and consuming mobility [1]. This fact makes it inevitable for automotive suppliers like Rheinmetall Automotive (RHA) not only to generate innovations with traditional methods and tools but also to predict new technology strategies and innovation management measures that drive their continuous growth in a challenging market environment [2].

Since the beginning of the 2010s, an increasing number of companies in the automotive industry recognized Open Innovation as an appropriate approach to renew their innovation strategy $[3,4]$. Therefore, technology strategy planning and innova- 
tion management have to find, select and implement adequate activities for the integration of more external stakeholders like startups, the establishment of networks and the opening of innovation to partners [2].

Thus, RHA decided to apply Open Innovation for extending the internal research and development procedures. In fact, they decided to adopt an outside-in approach of Open Innovation [5] by implementing Corporate Venturing (CV) in order to integrate startups in the Technological Direction Development Process (TDDP) [2] for enriching their technology foresight and innovation management, and increasing the innovative output of the company from an entrepreneurial point of view.

This paper outlines how RHA uses CV for boosting their innovation power. It starts with a literature analysis that focuses on Open Innovation on a very general level, as well as on CV and its strategical purpose and heterogeneous nature. Section 3 specifies the conceptual framework of this research including the objectives as well as the methodology. Section 4 presents the company-specific strategic model for $\mathrm{CV}$ at RHA. This model gives an understanding and guidance to RHA's management team on what prerequisites-based on defined strategic goals for CV-are necessary to make design choices for startup engagement programs and what kind of following actions have to be taken into account after the end of such programs. The last section draws the conclusion of this paper.

\section{$2 \quad$ Literature Review}

\subsection{Corporate Venturing - A Worldwide, Cross-Industrial Phenomenon}

At the beginning of the $21^{\text {st }}$ century, several factors changed companies' $R \& D$ behaviors and transformed the generally dominating Closed Innovation paradigm into an Open Innovation paradigm. Nowadays, $\mathrm{CV}$ is a widespread form of Open Innovation. Henry Chesbrough, who coined Open Innovation in 2003, identified the following four factors as the main reasons for the shift: skilled workers and their valuable knowledge, venture capital, external options for ideas on the shelf, as well as the capability of external suppliers [5].

In 2008, a very insightful study was published by Cooper and Edgett [6], who tried to find an answer to the question: "Ideation for Product Innovation: What are the best methods?" Their study looks at 18 different ideation methods with the objective to determine how extensively each ideation method is used (the popularity of the method) as well as to gauge management's perception of the effectiveness of the method in generating excellent, high-value new product ideas. A total of 160 companies took part in the study conducted in 2007 [6]. Their findings were summarized in the socalled "Magic Ideation Quadrant Diagram" which gives a good overview of the popularity and effectiveness of voice-of-customer methods, Open Innovation approaches and other ideation approaches. The interest thing about this study is that in the year 2007, Open Innovation activities, like e.g. forming startups, were still located in the lower half of the magic ideation quadrant diagram and therefore lower-rated. At that 
time, the Open Innovation methods received positive comments only from a small sub-set of users [6].

However, one decade later things have completely changed and Open Innovation strategies-especially CV activities-have increasingly found their ways into business practice. Over the last few years, numerous established companies have launched programs for interacting with entrepreneurial startups and internalizing these external opportunities [7,8]. This is proven by e.g. the Global Accelerator Learning Initiative (GALI) which listed 574 accelerators worldwide in February 2019 [9]. Kanbach and Stubner give a very good overview about the variety of this phenomenon and the lack of understanding of the various objectives and approaches adopted by companies $[8,10]$.

\subsection{Strategic Dimensions of Corporate Venturing}

Existing literature on CV only provides a limited and high-level understanding embedded in the larger context of literature on corporate entrepreneurship [10]. Kanbach emphasize two main research fields that deserve more attention within CV: the heterogeneity and the strategic objectives of CV activities [10]. There are several types of CV, and the use of a specific form of CV depends on the strategic goal of the hosting company. To find a suitable form of $\mathrm{CV}$, six strategic dimensions of $\mathrm{CV}$ have to be considered [10]:

1. Objectives (strategic vs. financial);

2. Investment intermediation (direct vs. indirect);

3. Equity involvement (yes vs. no);

4. Locus of opportunity (internal vs. external);

5. Strategic logic (exploration vs. exploitation);

6. Link to extant capabilities or organization (tight vs. loose).

$\mathrm{CV}$ can be based on financial or strategic objectives. Companies with a pure financial objective only aim for financial returns. The most common way of financially driven $\mathrm{CV}$ is the use of corporate venture capital funds to invest in a portfolio of startups [11]. The startups are in the most cases not directly linked to the core business in terms of strategy but are expected to result in a positive return on investment (ROI). Next to financial objectives, $\mathrm{CV}$ can be strategically driven. According to Kohler [12], corporates could for example engage in a pilot project, a suppliercustomer relationship or distribution partnership. Since the outcomes of strategic CV are expected to connect startups with the parent company, it targets startups that are in relevant markets and segments. Generally, it can be said that CV ultimately always targets a financial goal in some way as it aims for increasing the innovation of the company and thereby strengthening the competitive advantage that results in a sales increase or cost reduction [10].

$\mathrm{CV}$ can have different investment mediations. This means that companies differ in their investment approach. Companies can either invest directly in a startup or invest indirectly by using a corporate venture capital fund. These two options of investment have different levels of risk and control [13]. 
$\mathrm{CV}$ activities vary in the involvement of equity. Companies taking equity in startups often benefit from control, but increase management complexity as well. In comparison, companies with no equity involvement have less liability in the company and less management complexity, but lack control. Weiblen and Chesbrough state that the mandatory involvement of equity became less common in new and modern $\mathrm{CV}$ activities [7].

CV differs in the locus of opportunity. Here, the locus can be internal or external. With an internal locus of opportunity, CV targets ideas gathered within the parent company. With an external locus of opportunity, CV searches for ideas outside the company borders. This differentiation has already been part of Chesbrough's Open Innovation model and refers to the outside-in and inside-out approaches [5].

CV can either have an exploiting or exploring strategic logic. Exploiting activities focus on resources, technologies and competencies that are already available within the company [10]. Here, the goal is to maximize the use of these resources, technologies and competencies to enter adjacent markets for example to increase revenue. In comparison, exploring activities focus on gaining new resources, technologies and competencies to extend the company's portfolio and enter new markets [10]. Whereas exploring activities often provide uncertain and less controllable results that are rather long-term oriented, exploiting activities mostly result in predictable and immediate outcomes. It can be concluded that exploiting activities have a higher intent for financial results and exploring activities are based on strategic objectives [10].

CV activities differ in the link to the partner's capabilities or organization. This refers to the usage of the parent company's resources and processes [11]. Startups that have a tight link to the parent company could use the available channels, facilities and other resources, whereas a loose link separates the startups more. On the one hand, parent company's resources and processes could boost a development of a startup. On the other hand, it could also hinder and limit the performance and development of a startup due to related bureaucracy and policies. Again, this dimension can be linked to the dimensions before, as a startup that is tightly linked rather focuses on exploiting whereas a loose link between parent company and startup would mostly imply activities focused on exploring [10].

To use CV most effectively and efficiently, companies have to select a form that fits their strategic goals for CV. Therefore, a company that considers launching CV has to make decisions in all six strategic dimensions to find a suitable form of $\mathrm{CV}$. Additionally, the correct use of CV depends on the startup's stage in its lifecycle, since the different forms focus on specific lifecycle stages of a startup.

\subsection{Lifecycle Stages of a Startup}

The lifecycle of a startup can be divided in five stages [14]. Each stage is related to resources that a startup requires for surviving and growing.

The first stage is the problem-solution fit. This stage is often referred to as ideation phase and is the very beginning of a startup. In this stage, entrepreneurs detect problems and formulate the business idea that solves these problems. This stage can be 
seen as the first step and base of a business plan. Moreover, the problem-solution fit needs research to proof that the idea fits a certain problem.

The second stage is the minimum viable product (MVP). A MVP is the smallest and most low-cost visualization of an idea [15]. Nevertheless, building a MVP can be costly depending on the technology or kind of idea and often requires a certain amount of capital. It is used to be presented to the target group to get a first feedback and to further investigate on demand and the requirements of the target group. At the end of this stage, more capital is needed to develop the MVP further and transform it into a real prototype.

The third stage is the product-market fit. At this stage, the prototype becomes a product and is launched in the market. Consequently, first customers and sales are generated. This stage is used as a first real-life test and the reactions of customers are collected and analyzed to further improve the product if necessary. At the end of this stage, a startup made its first step into the market and positioned its product.

The fourth stage is the business scaling. This stage is crucial and defines the future of a product. It requires extensive marketing and other support to get people buying the product. It is about scaling up the business and increase sales and number of customers. Only a few startups achieve the required growth to become a big player in the market and be profitable in the long-term.

The fifth stage is the maturity of a business. At this stage, the startup has reached a certain level of growth and market share. From now, the growth rates usually slow down. Nevertheless, further investments, strategic changes and a high level of innovation can boost the growth again. Facebook and Google are examples of companies that still present significant growth rates [15].

\subsection{Five Distinct Types of Corporate Venturing}

Based on these findings from literature, we distinguish between five distinct CV types that can be chosen depending on the applicable strategic dimensions of a company concerning $\mathrm{CV}$ and its criteria on the scouting startups. Each type of CV provides an approach to foster innovation within a company, has certain characteristics and can take therefore different forms. These types of $\mathrm{CV}$ are:

1. Corporate Venture Capital: Corporate Venture Capital (CVC) is an investment activity in which a corporation makes an equity investment in external startups [11]. The investments can be direct or covered by a venture capital fund [16]. CVC can be driven by strategic or financial objectives and can target startups with a loose or tight link to the operational capability of the parent company. CVC investments can be driving, enabling, emergent or passive [11].

2. Incubator: The incubator model can be derived from the term incubation that refers to supporting an entrepreneur during the idea-to-market process. Incubators are long-term programs that support early stage ventures in their idea-to-market process. The support therefore ranges from defining the business model to administrative and legal support in the startup setup phase until the access to technology, equipment and networks to create a MVP or prototype and realize the business plan. Additionally, incubators also provide entrepreneurs with funding opportuni- 
ties and basic assets like shared spaces and computers. Incubators can differ in various aspects. First, incubators can support the whole idea-to-market process or focus on specific stages of incubation. Here, pre-incubators and general incubators can be found. Secondly, incubators can be market specific or target a broad field of markets. Thirdly, incubators can vary in their nature of service as "Enterprise Hotels", for example, concentrate on physical incubation. Fourthly, incubators differ in their ownership. Business Innovation Center, University Business Incubator, Independent Private Incubator and Corporate Private Incubator are the most used and common forms [17].

3. Accelerator: The accelerator is the most recent type of $\mathrm{CV}$ and can be seen as a development or special configuration of the business incubator. It supports cohorts of mostly late stage startups in scaling up in a time frame of three to six months on average. The most recent form of acceleration is the corporate accelerator. This is a company owned private accelerator that follows the structure of a classic accelerator. It is divided into an application, selection and project phase and ends with a demo day. It supports startups with mentoring, education and company-specific resources. The outcomes of a corporate accelerator are mostly strategic partnerships and cooperation but can vary depending on the objectives of the hosting company. Four forms of accelerators can be identified: Listening Post, Value Chain Investor, Test Laboratory and Unicorn Hunter [8].

4. Innovation Lab: The innovation lab is a physical or digital environment to co-work and grow ideas. Its goal is to develop and test business models by integrating different stakeholders as even customers. Differences in objectives and ownership result in five forms of innovation labs: Grassroot Lab, Coworking Lab, University Lab, Corporate Lab and Company Builder [18].

5. Hackathon: Hackathons are hardware and software development events with limited time duration between one day and one week. Hackathons can be either techcentric and focus on a specific technology or challenge or focus-centric and used to solve a social or business problem. In the last time, the number of less technical participants as marketers, business developers and designers increases [19].

In summary, literature review shows that $\mathrm{CV}$ is not uniform and diverse types and forms of CV exist, each of which follows different strategic dimensions. The research work of Kanbach and Stubner [8,10] explains very well how important the link between the definition of the objectives and the design configuration of the $\mathrm{CV}$ program are. This is an important success factor that we want to consider in our research work.

\section{Conceptual Framework of the Research}

\subsection{Research Objective}

The aim of this research work is to further increase innovation within RHA by using CV. These CV activities should be embedded in the existing TDDP [2] at RHA and the recommendations will include strategic considerations corresponding to the 
objectives of RHA in view of CV. Defining clear objectives is very crucial success factor for CV [8] and will help RHA by designing its startup engagement.

Therefore, in a first step RHA's strategic goal for CV will be outlined to then evaluate the fit of different forms of CV. The final formulation of a company-specific strategy model for CV will provide RHA guidance for planning CV activities more effectively and efficiently in future.

\subsection{Methodology}

We can formulate our central research question as follows: How can RHA use CV to increase innovation? This general research question leads to the following subquestions:

1. What is RHA's strategic goal for CV?

2. Which form of CV should RHA use?

3. How can CV be introduced at RHA?

The solution to a practical problem is clearly positioned at the center of this research work stands. This general pragmatic orientation allows using mixed methods research [20]. Therefore, this research combines two qualitative data collection methods: literature review and expert interviews. The first part of the chosen multi-method research includes the analysis and evaluation of secondary data, like available publications and presentations. For the second research part the choice of the suitable method to capture the data fell on the qualitative, guided expert interview [21], because the findings from the desk research should be complemented and validated. Both research methods, literature review and expert interview, will be analyzed together and the findings will influence each other.

Our research seeks to link theoretical principles with industry experiences to close the information gaps and will finally culminate in our case study at RHA to explore profoundly real-life events [22] and provide RHA a company-specific solution.

\subsection{Data Collection and Analysis}

Following the above defined research question and its sub-questions we can outline our process of data gathering and analysis in the following main research steps.

First, RHA's strategic goal for Open Innovation and in detail CV was defined. This served as a base for the evaluation of CV forms. The strategic goal includes both the motivation for using CV and the criteria for startups that RHA would engage with. To get a complete view on the strategic goal, experts of the innovation management and business development department were interviewed. Additional information was gathered from an interview with an external innovation catalyst that supported RHA during activities of startup engagement.

Secondly, forms of CV that fit RHA's strategic goal were identified. In a first step, different types and forms of $\mathrm{CV}$ were described and reviewed based on desk research. In a second step, each form was analyzed and evaluated against its fit with the strategic goal of RHA. 
Thirdly, a company-specific strategic model for CV at RHA was defined. This includes CV forms that fit RHA's strategic goal for CV best. Additionally, prerequisites for introducing $\mathrm{CV}$ at RHA have been outlined.

\section{$4 \quad$ A Strategic Model for Corporate Venturing}

\subsection{RHA's Expectations in Corporate Venturing}

RHA represents organizations wanting to integrate startups in the innovation process for product development and diversification. Therefore, it is crucial to clarify the criteria that a startup has to fulfil to be a potential stakeholder in RHA's innovation process. RHA defined criteria regarding the markets where the startups have to be positioned in. These target markets are aligned with RHA's strategic directions and objectives.

Furthermore, RHA specified maturity requirements for startups in terms of their business plans, product viability, pilot customers, business networks, and growth estimation. All startup employees have to be highly committed and share a common vision led by an experienced management team.

\subsection{The Strategic Model for Corporate Venturing at RHA}

A single form of $\mathrm{CV}$ is not able to cover all the expectations cited above. Therefore, a strategic model describing how to use different forms of CV to increase innovation has been developed (Figure 1). The strategic model separates the two objectives of product development and diversification and links both with individual CV forms. It contains three main parts: 1 . configure $\mathrm{CV}$ program, 2. select $\mathrm{CV}$ form and 3. organize next steps.

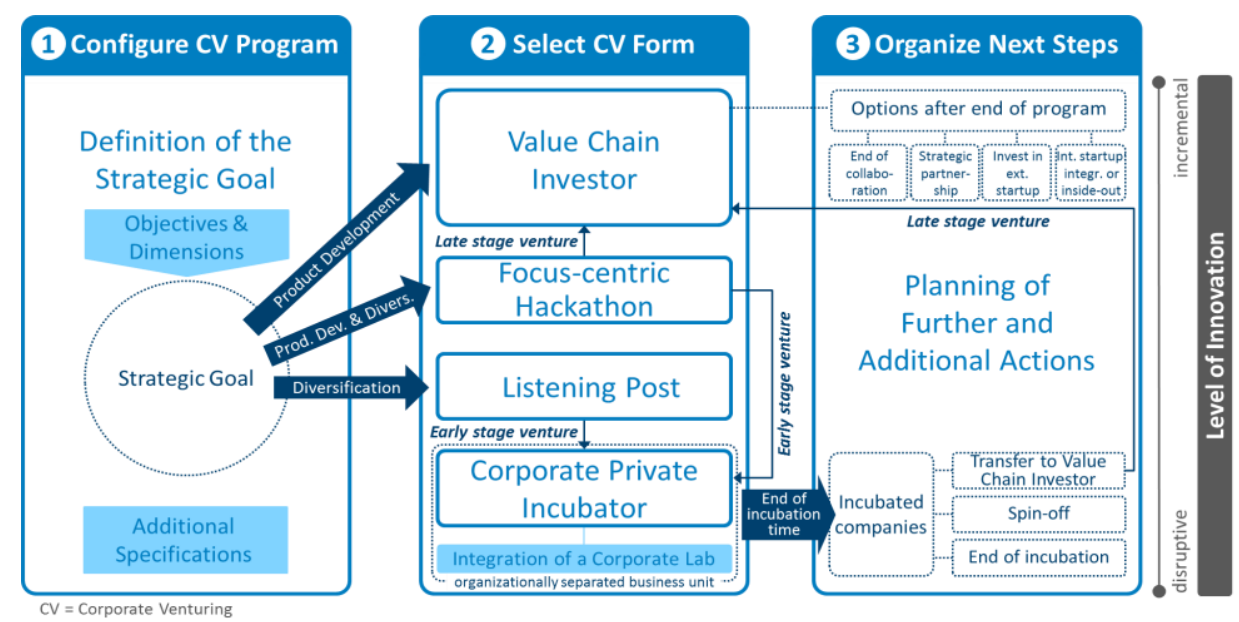

Fig. 1. A Strategic Model for Corporate Venturing 
The first part of the strategic model is dedicated to the configuration of the CV program. It focuses on the definition of the strategic goal, which highly affects the choice of a form of $\mathrm{CV}$ and has to fit its characteristics. Therefore, a clear definition of the strategic goal is crucial for the effectiveness and efficiency of the strategic model. The definition of the strategic goal includes the setting of objectives and dimension. This refers to the strategic dimensions explained in section 2.2, and defined specifically for RHA in the project. In addition to the strategic dimensions, other adjustments and specifications can be made. For example, RHA defines technology search fields and criteria that a startup had to fulfil. This step also includes the consideration of the time factor, as this differs between $\mathrm{CV}$ forms.

The second part of the strategic model refers to the selection of one or more fitting $\mathrm{CV}$ forms. Most promising CV forms for RHA are:

1. Value Chain Investor. This CV form targets late stage startups and its goal is to integrate them in the value chain of RHA after the program. The acceleration phase takes three to six month. Within the Value Chain Investor, RHA can link the startups with product or market related business units to make them define a use case together and start a pilot project. Here, it has to be mentioned that the closer the startups technology is to RHA's business, the easier is it to find a use case and start a pilot project. The use case could be of different nature. RHA and the startup could test a customer-supplier relationship, a sales distribution partnership or the direct integration of the technology or product into a system or product of RHA. There could be several other possible use cases depending on the business unit and especially the startup. The Value Chain Investor is used to cover RHA's objective of product development as it establishes a fast and less risky way to test and integrate incremental innovations. This is due to the maturity of the startup and the time limited program.

2. Focus-centric Hackathon. The concept of a Focus-centric Hackathon is to challenge participants with a problem that a company wants to be solved. Therefore, the participants provide solutions individually or in teams within one day to one week. The hackathon usually targets early stage software or hardware developers. Furthermore, a hackathon could be used to search for incremental innovation as well as disruptive innovation. Therefore, the Focus-centric Hackathon could provide the diversification based incubator as well as the product development based Value Chain Investor with innovative startups. Finally, it can be used to scout startups in case of a specific and detailed search field or problem.

3. Listening Post. This CV form scouts market trends and emerging technologies. It targets early stage ventures and does not require investments and equity involvement. Here, the detailed definition of search fields determines the search radius of the Listening Post. Its characteristics make the Listening Post a perfect tool for RHA's objective of diversification. As described earlier, RHA has to redefine its criteria for startups to use the Listening Post as a contact point that is open for startups on a regularly basis. If a promising early stage startup or technology is detected in the Listening Post, it gets transferred in the Corporate Private Incubator. 
4. Corporate Private Incubator. Here, the early stage ventures receive support in business plan development as well as basic administration, mentoring and coaching. Startups that get into the corporate private incubator were scouted either in the Listening Post or in the focus-centric hackathon. The final deliverable of an incubator is the creation of a minimal viable product or prototype at the end of incubation time. At this stage it is important to make an equity investment to ensure control and access to the disruptive innovation and commitment. Additionally, a Corporate Lab is part of the incubator. Startups can use shared equipment and machinery to work on minimal viable products and prototypes. Companies, that origin from the hackathon are most likely of digital and software nature. Therefore, the Corporate Lab also provides a digital environment to further work on the digital solutions. The access to funding plays an important role in this stage as well. The investments have to be made in exchange for equity. This ensures control and commitment from both sides. Consequently, CVC is included in a way. From an organizational perspective, the incubator is owned by RHA but functions as a separate legal identity. This has to be ensured to prevent the startups from facing corporates obstacles like decision making processes and bureaucracy that could hinder the development of the startups. Another important advantage considers the locus of opportunity. Theoretically, company internal ideas could be evaluated and transferred into the incubator as well. This supports the entrepreneurial climate within RHA and encourages employees to be creative together [23], which is also a major trait of the SPI Manifesto [24]. Finally, ideas that went through the incubator and reached a certain level of maturity, get into the Value Chain Investor and follow the process as explained in the third component.

The third part of the strategic model aims the organization of the next steps. This part covers further and additional actions regarding a startup after finishing the Value Chain Investor and/or Corporate Private Incubator. At the end of the incubation time, a startup can follow three ways. It can be transferred to the Value Chain Investor and participate in the Value Chain Investor program for further progress. If a startup is highly promising and very innovative but cannot be linked to any business unit of RHA, it can be treated as a spin-off. If a startup does not perform well within the incubator, it will be removed from the program. After finishing the Value Chain Investor, startups have four options. First, the collaboration can be stopped. This option can be chosen if the pilot project or use case definition within the Value Chain Investor does not perform as expected. Additionally, collaboration could be stopped due to changes in the strategic goal. Secondly, the startup and RHA could engage in a strategic partnership. This could be the reason in case of a successful phase in the Value Chain Investor. Thirdly, investments or even acquisitions can be made. This option especially relates to external startups. Fourthly, internal startups, that made it into the Value Chain Investor through the incubator, could be integrated by RHA into one or more existing business units. Otherwise RHA can follow an inside-out approach and sell or license the internal startups. 


\subsection{Prerequisites for Introducing Corporate Venturing at RHA}

A clear and realistic expectation management is crucial. A company has to be aware of the results that it can expect in each stage in the lifecycle of a startup and in each form of CV. This also affects the performance measurement of the strategic model. RHA cannot expect to measure the Corporate Private Incubator and the Corporate Lab with classic financial measures and key performance indicators. Here, it can rather measure the performance of the incubator by considering the number of startups that were transformed into the Value Chain Investor or spin-offs. In case of the Value Chain Investor, financial key performance indicators could be more applicable. RHA could for example measure the financial benefits that a successful collaboration generated.

Furthermore, every form of $\mathrm{CV}$ requires buy-in from business units and more important top-level management. This has been confirmed by several research projects and also in the expert interviews with RHA. Without the support of top-level management, engagements in CV will fail [8]. This can be due to a lack in financial or human resource support that has to be distributed and confirmed by a business unit leader or a higher management level. Therefore, the Value Chain Investor, for example, integrates the business unit leaders intensively and in the strategic goal definition already. At RHA, this could be achieved by embedding the strategic model for CV in the already existing TDDP. The strategic goal for CV is also aligned with the general strategy of RHA and therefore aligned with management decisions. Next to that, a program management team has to be appointed. This team has the role of a contact point for all stakeholders to then allocate problem questions that cannot be answered or solved directly in the program. Moreover, CV will be related to costs. These costs are of different nature in each CV program. While the Value Chain Investor requires capital for pilot projects, the Corporate Private Incubator requires intensive capital for the definition and realization of a business plan and model including a MVP or prototype. Consequently, CV, and each form of it, has to have a certain budget available. Furthermore, the probability of detecting a promising startup in any of the programs increases with the quality and quantity of startups that apply. Therefore, it is crucial to establish and continuously develop an entrepreneurial network around the company to leverage as many sources as possible. Here, collaborations with universities or other educational institutions as well as other external sources like innovation catalysts have to be generated. This important collaborative aspect of innovation management is in alignment with the recommendations of the new ISO 56003 standard on innovation management [25].

It is important to integrate the top-level management and technology roadmap into the strategic goal definition, the selection of the CV form and the planning of further and additional actions. For example, the business unit leaders and-additionally-the market research department can be integrated. The integration of the business unit leaders could be valuable for the search field definition of the Value Chain Investor. For the detection of new markets for the Corporate Private Incubator, the integration of the market research department can deliver further insights for profitable search fields. Next to that, detailed operational planning considering the amount of startups, 
the budget for the programs as well as the timeframe for each program needs to be defined.

\section{Conclusion}

The need for new mobility solutions requires new strategies for innovation coming up with new technologies or services, new business models, new stakeholder networking strategies, new innovation roadmapping methods, etc. Therefore it is indispensable for companies from the automotive supplier industry like RHA to enrich their established innovation management by implementing new concepts of CV in their technology strategy planning. RHA sees a possible answer to the question "How can RHA use CV to increase innovation?" by enforcing startup engagement and introducing a strategic model for CV like the one we described in this paper.

We presented different forms of $\mathrm{CV}$, and how these can be applied in a structured way based on an integrated strategic model developed at RHA. This strategic model uses different forms of CV for leveraging both incremental innovation and diversification. To be applied effectively, it requires a clear and realistic expectation management, as well as the integration of top-level management to ensure the access of resources and prevent internal obstacles. Each CV form and each startup stage needs a specific setup and delivers different results.

Validated at RHA with success in its initial phases, we see that our strategic model significantly improves RHA's technology strategy planning and innovation management. On this basis, we consider that perspectives for future research activities directly linked to the enhancement of the strategic model, as well as to the determination of the applicability of the approach in other organizational contexts and industry sectors are given.

\section{References}

1. Dismon H., Seggewiß P., Hunkel D. (2018). Innovative Elektrifizierungstechnologien für zukünftige konventionelle und alternative Fahrzeugantriebe - Innovative Technologies for the Electrification of Future Conventional and Alternative Vehicle Powertrains. In: Geringer B., Lenz H.P. (Eds.): 39th International Vienna Motor Symposium 26-27 April 2018; Volume 2: second day, Fortschritt-Berichte VDI Reihe 12, Nr. 807, Proceedings, pp. 268290, VDI Verlag Düsseldorf 2018.

2. Neumann M., Riel A., Dismon H. (2018). Technology Strategy Planning and Innovation Management at Rheinmetall Automotive to Face Future Mobility Challenges. In: Larrucea, X., Santamaria, I., O'Connor, R.V., Messnarz, R. (Eds.): Systems, Software and Services Process Improvement - 25th European Conference, EuroSPI 2018, Bilbao, Spain, September 5-7, 2018, CCIS 896, Proceedings, pp. 607-618, Springer-Verlag, Berlin Heidelberg 2018.

3. Ili S., Albers A., Miller, S. (2010). Open innovation in the automotive industry. In: R\&D Management, Vol. 40, No. 3, pp. 246-255. 
4. Lazzarotti V., Manzini R., Pellegrini L., Pizzurno E. (2013). Open Innovation in the automotive industry: Why and How? Evidence from a multiple case study. In: Int. J. Technology Intelligence and Planning, Vol. 9, No.1, pp. 37-56.

5. Chesbrough H.W. (2003). Open Innovation: The New Imperative for Creating and Profiting from Technology. Harvard Business School Press, Boston, Massachusetts.

6. Cooper R.G., Edgett S.J. (2008). Ideation for Product Innovation: What are the best methods? In: PDMA Visions Magazine, Vol. 32, Iss. 1, pp. 12-17.

7. Weiblen T., Chesbrough H.W. (2015). Engaging with Startups to Enhance Corporate Innovation. In: California Management Review, Vol. 57, No. 2, pp. 66-90.

8. Kanbach D.K., Stubner S. (2016). Corporate Accelerators As Recent Form Of Startup Engagement: The What, The Why, And The How. In: The Journal of Applied Business Research, Vol. 32, No. 6, pp. 1761-1776.

9. Global Accelerator Learning Initiative (2019). Directory of accelerators worldwide [online] Available at: https://www.galidata.org/accelerators/directory/ [Accessed February 19, 2019].

10. Kanbach D.K. (2016). Corporate Venturing Activities of Established Companies. Dissertation. http://nbn-resolving.de/urn:nbn:de:bsz:14-qucosa2-78151, HHL Leipzig Graduate School of Management, Leipzig.

11. Chesbrough H.W. (2002). Making Sense of Corporate Venture Capital. In: Harvard Business Review, Vol. 80, No. 3, pp. 90-99.

12. Kohler T. (2016). Corporate accelerators: Building bridges between corporations and startups. In: Business Horizons, Vol. 59, Iss. 3, pp. 347-357.

13. Markham S.K., Gentry S.T., Hume D., Ramachandran R., Kingon A.I. (2005). Strategies and Tactics for External Corporate Venturing. In: Research-Technology Management, Vol. 48, Iss. 2, pp. 49-59.

14. Medium.com (2016). 5 Phases of the Startup Lifecycle: Morgan Brown on What it Takes to Grow a Startup. [online] Available at: https://medium.com/tradecraft-traction/5-phasesof-the-startup-lifecycle-morgan-brown-on-what-it-takes-to-grow-a-startup-50b4350f9d96 [Accessed Feb 08, 2019].

15. Startplatz.de (2019). MVP - Minimum Viable Product. [online] Available at: https://www.startplatz.de/startup-wiki/mvp/ [Accessed February 08, 2019].

16. Boston Consulting Group (2012). How the best corporate ventures keep getting better. [online] Available at: http://image-src.bcg.com/Images/BCG-How-the-Best-CorporateVenturers-Keep-Getting-Better-Aug-2018_tcm9-200601.pdf [Accessed November 15, 2018].

17. Grimaldi R., Grandi A. (2005). Business incubators and new venture creation: an assessment of incubating models. In: Technovation, Vol. 25, Iss. 2, pp. 111-121.

18. Projekt Zukunft (2013). Innovations- und Kreativlabs in Berlin - Eine Bestandsaufnahme. Räume und Events als Schnittstellen von Innovation und Kreativität. [online] Available at: https://projektzukunft.berlin.de/fileadmin/user_upload/pdf/studien/130626_Innovations_und_Kreativlabs_in_Berlin_-_eine_Bestandsaufnahme.pdf [Accessed February 08, 2019].

19. Briscoe G., Mulligan C. (2014). Digital Innovation: The Hackathon Phenomenon. CreativeWorks London Working Paper No. 6, Arts and Humanities Research Council, London.

20. Creswell J.W., Creswell, J.D. (2018). Research design: Qualitative, Quantitative, and Mixed Methods Approaches. SAGE Publications Inc., 5th edition, Thousand Oaks, California.

21. Witzel A. (2000). The problem-centered interview [26 paragraphs]. Forum Qualitative Sozialforschung/Forum: Qualitative Social Research, Vol. 1. No. 1, Art. 22, [online] 
Available at: from http://www.qualitative-research.net/index.php/fqs/article/ view/1132/2521 [Accessed February 11, 2019].

22. Yin R.K. (2018). Case Study Research and Applications: Design and Methods. SAGE Publications Inc., 6th edition, Thousand Oaks, California.

23. Miller P., Brankovic A. (2011). Building a Creative Culture for Innovation. In: IESE Insight, Iss. 11, Fourth Quarter 2011, pp. 51-58.

24. Korsaa M., Johansen J., Schweigert T., Vohwinkel D., Messnarz R., Nevalainen R., Biro M. (2013). The people aspects in modern process improvement management approaches. Journal of Software: Evolution and Process, 25(4), 381-391.

25. Technical Committee ISO/TC 279, Innovation Management (2019). ISO 56003:2019(en) Innovation management - Tools and methods for innovation partnership - Guidance, International Organization for Standardization, [online] Available at: from https://www.iso.org/obp/ui/\#iso:std:iso:56003:ed-1:v1:en [Accessed May 13, 2019]. 